\title{
Use of Trabecular Metal Implants for the Rehabilitation of a Maxillary Edentulous Arch: A Case Report
}

\author{
Carlo Maria Soardi, ${ }^{\text {Emanuele Clozza, }}{ }^{\dagger}$ Davide Zaffe, ${ }^{\ddagger}$ and Hom-Lay Wang
}
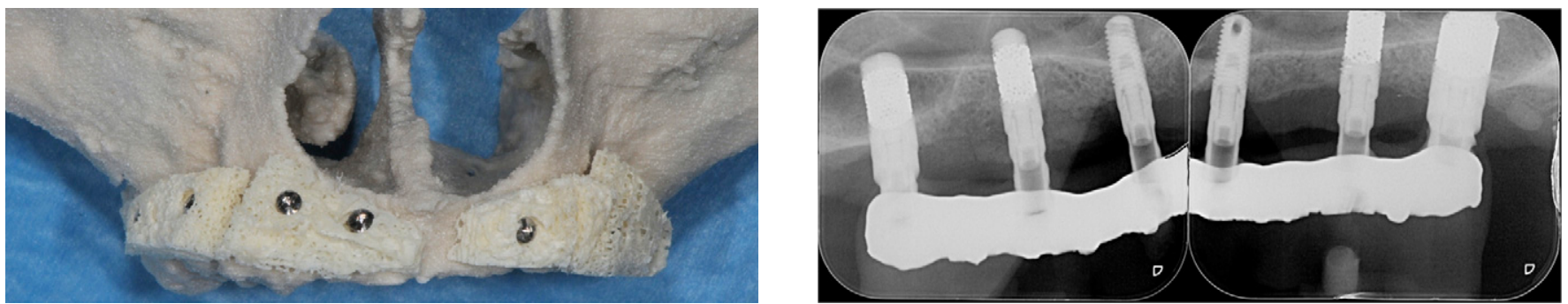

Background: This case report illustrates the use of trabecular metal (TM) implants to rehabilitate a severely atrophic maxillary arch that was successfully augmented by allografts.

Case Presentation: A 68-year-old female was referred to a private practice for severely maxillary alveolar bone atrophy (e.g., subsinus bone height of $<1 \mathrm{~mm}$ on the left side and $<4 \mathrm{~mm}$ on the right side). Allograft bone block augmentation was used to regenerate ridge deficiency simultaneously with bilateral sinus augmentation. Six implants (four TM and two tapered) were placed, and bone specimens were obtained 6 months after grafting. Radiography and histologic analysis demonstrated that implants were positioned in non-native bone. Removal torque test, performed at the second-stage procedure, confirmed the successful osseointegration of implants. The definitive implant-supported full-arch prosthesis was then constructed and placed in function.

Conclusion: The positive outcomes of this case report suggest that the rehabilitation of severely atrophic maxillary arch might be achieved by merging TM with new regenerative techniques without harvesting extensive quantities of autogenous graft. Clin Adv Periodontics 2014;4:167-174.

Key Words: Bone regeneration; bone transplantation; histology; sinus floor augmentation; tantalum; transplantation.

\section{Background}

The surface topography of implants, mainly consisting of commercially pure titanium, has been thoroughly investigated and significantly improved in the past two decades. ${ }^{1}$ Recent advancements have led to the development a new trabecular metal (TM) implant" composed of tantalum. Tantalum possesses characteristics that confer significant advantages over traditional implant materials: it is chemically stable and biocompatible and can be manufactured with a three-dimensional (3D) architecture similar to that of bone trabeculae. ${ }^{2}$ In addition, it presents favorable strength even in its trabecular form. ${ }^{2}$ Studies in humans and animals have shown excellent bone ingrowth into the trabecular bone holes. ${ }^{3-6}$

\footnotetext{
* Private practice, Brescia, Italy.

${ }^{\dagger}$ Department of Periodontology and Implant Dentistry, New York University College of Dentistry, New York, NY

‡ Department of Biomedical, Metabolic, and Neural Sciences, University of Modena and Reggio Emilia, Modena, Italy.

$\S$ Department of Periodontics and Oral Medicine, School of Dentistry, University of Michigan, Ann Arbor, MI.
}

Submitted December 29, 2012; accepted for publication March 8, 2013
In orthopedics, the use of tantalum is recommended in areas in which the bone quality is questionable. ${ }^{7,8}$ Focusing on implant dentistry, the native implant site may present an inadequate bone quantity and quality as a result of previous extractions, periodontal disease, or traumatic injuries. When these situations occur, regeneration of the implant site is often the solution.

The use of human bone for the regeneration of osseous defects has significantly changed implant dentistry in the past 20 years. ${ }^{9}$ Autologous bone has been recognized as the gold standard of bone graft material because it possesses osteoconductive, osteoinductive, and osteogenic properties. ${ }^{10}$ However, harvesting bone from patients presents many disadvantages, including morbidity of the donor site and high risk of severe complications. ${ }^{11}$ Moreover, the supply of autologous bone graft may be limited. ${ }^{11}$ Clinicians are continually searching for alternative grafting materials resembling the properties shown by autologous bone. Allografts, which are available in ample quantities and in many different forms including powders, granules, putty, and blocks, enable clinicians to offer therapeutic solutions that are less invasive and more effective, which significantly minimizes biologic and economic cost for the patient.

" Trabecular metal implant, Zimmer Dental, Carlsbad, CA. 
Based on the aforementioned considerations, the present case report describes the insertion of TM implants in a purely augmented site.

\section{Clinical Presentation}

A 68-year-old female was referred to a private dental office in Brescia, Italy with the chief complaint of maxillary edentulism (Fig. 1a). She was systemically healthy and did not smoke and or take any medications. At the time of the initial consultation, the patient wore a removable complete upper denture. Upper and lower alginate impressions were taken. A full diagnostic wax-up was performed on the mounted study model casts (Fig. 1b).

A preoperative cone beam computed tomography (CBCT) scan was taken (Fig. 2). The 3D CBCT data provided the information to fabricate a solid model (Fig. 3) according to a technique described in a previous report. ${ }^{12}$

The clinical and radiographic examination of the maxillary alveolar ridge revealed a Seibert Class III ridge deficiency defect. ${ }^{13}$ Moreover, preexisting subsinus alveolar bone height was $<1 \mathrm{~mm}$ on the left side and was only 1 to $4 \mathrm{~mm}$ on the right side.

The patient declined an invasive treatment option that required onlay/inlay autogenous grafts; therefore, allograft bone block augmentation was planned to regenerate ridge deficiency on both sides of the maxilla, contextually with bilateral sinus augmentation.

A fixed implant-supported full-arch hybrid prosthesis, Toronto bridge type, ${ }^{14}$ was planned for the upper arch. The active treatment was performed from October 2011 to

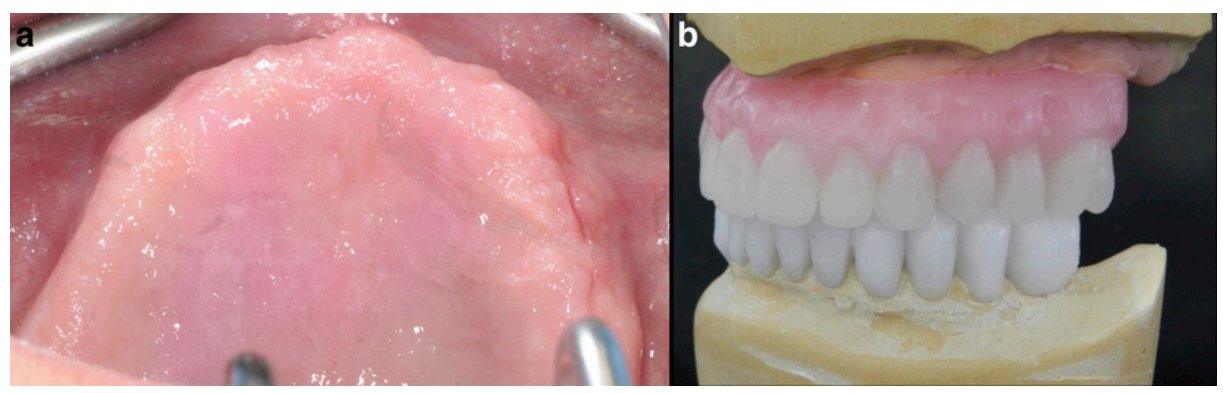

FIGURE 1a Initial presentation. 1b Diagnostic wax-up

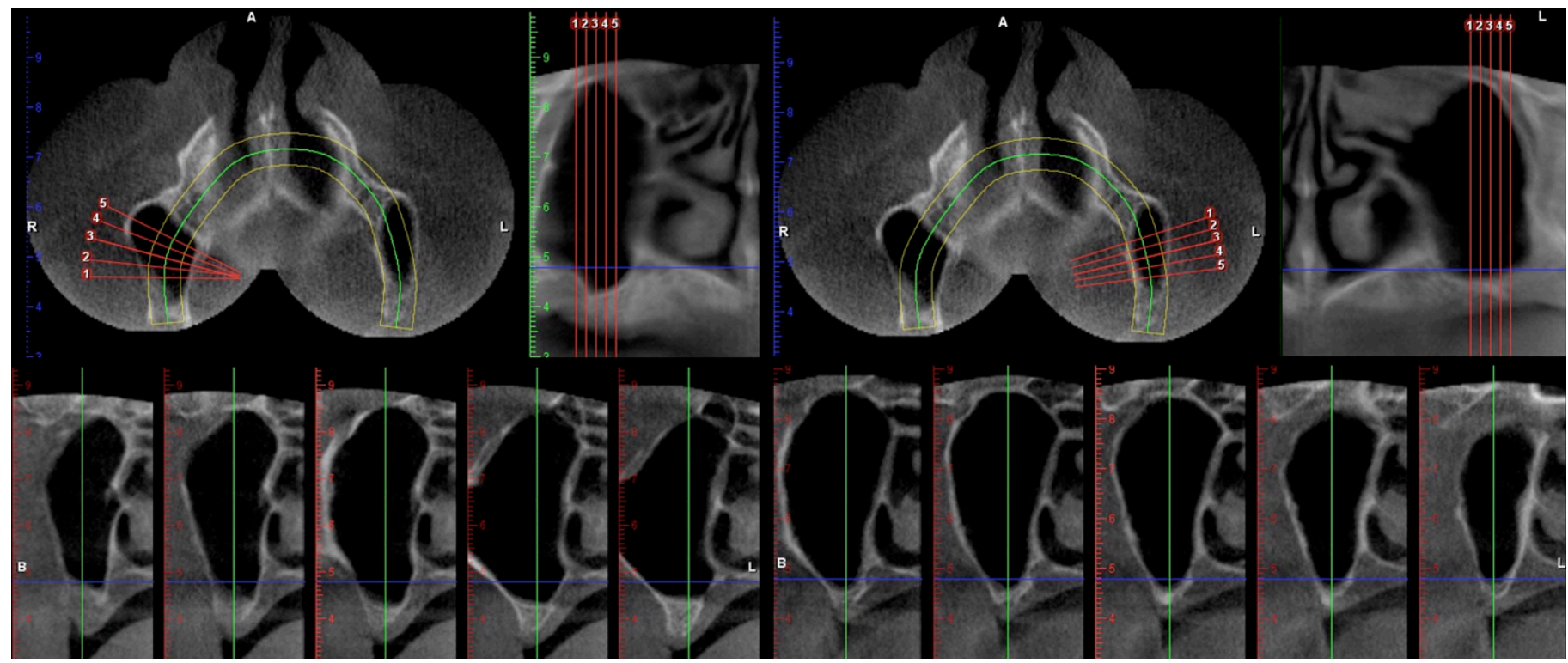

FIGURE 2 Preoperative CBCT scan.

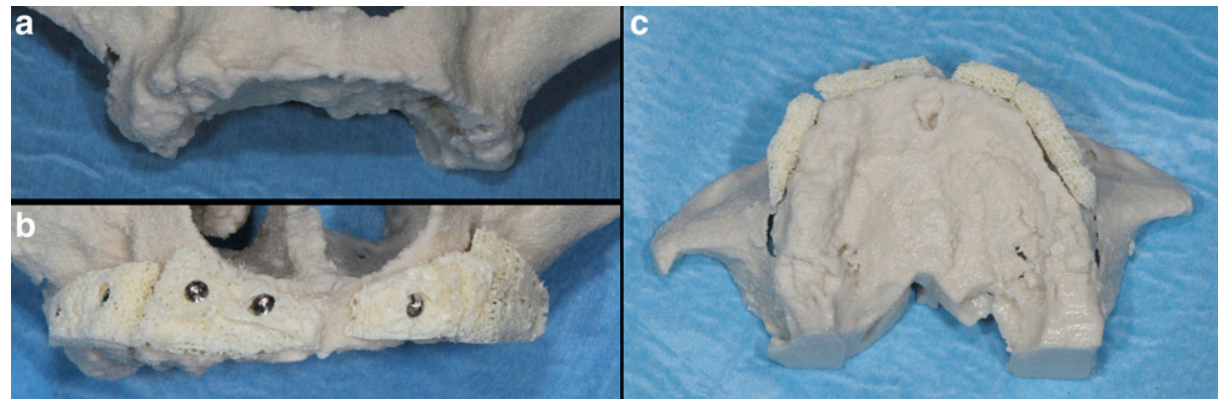

FIGURE 3 Sinterized models. 3a Front view. 3b Front view. Prepared segments were attached to the sterile sinterized model. $3 \mathrm{c}$ Occlusal view. 

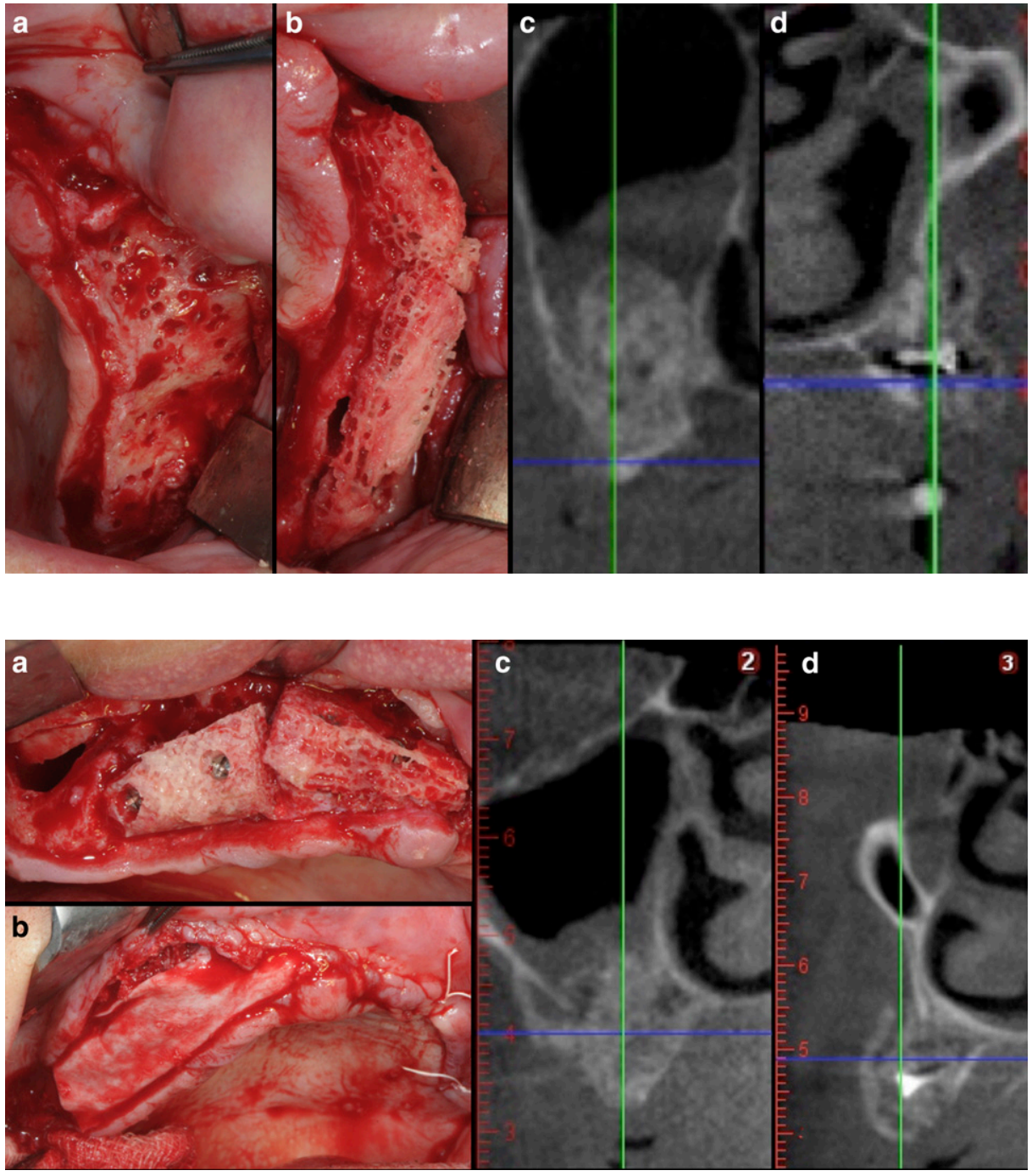

FIGURE 4a Corticotomy. 4b Allograft segments were transferred from the model to the recipient site. 4c and 4d Immediate postoperative CBCT scan.
November 2012 by the same operator (CMS). The patient agreed to the treatment and signed a written consent form.

\section{Case Management}

Surgical sites were infiltrated by local anesthetic with epinephrine concentration of 1:100,000. Two horizontal mid-crestal incisions were made lightly palatal to the crest of the ridge, from both distal aspects of the maxilla, continuing mesially until they reached each other anteriorly. A buccal full-thickness flap was reflected to expose the residual ridge and the lateral wall of the right-sided sinus. Transcrestal approach was used to augment the left-sided sinus floor, whereas the right-sided one was approached laterally, as previously reported. ${ }^{15}$ Preparation of the allograft and the onlay grafting technique was done as described in a previous report. ${ }^{12}$ The cortical plate of the recipient bone was perforated to induce bleeding (Fig. 4a).

Block bone grafts" were positioned to augment the buccal side of the residual ridge and at the same time to cover the crestal window (Fig. 4b). Allografts were stabilized in place with miniscrews** (Fig. 5a). Remaining voids between blocks were filled with particulate graft. ${ }^{+\dagger}$ Bone graft materials were covered with pericardium membrane ${ }^{\ddagger \ddagger}$ to prevent epithelial ingrowth (Fig. 5b). Flaps were repositioned after buccal periosteal incisions and stabilized with single interrupted sutures $\$ \S$ to achieve primary wound coverage. A CBCT scan was taken immediately after grafting (Figs. 4c, 4d, 5c, and 5d). The patient was given $500 \mathrm{mg}$ amoxicillin"II twice daily for 7 days to control infection and $550 \mathrm{mg}$ naproxen $\%$ for pain and inflammation. The patient was instructed to use $0.12 \%$ chlorhexidine ${ }^{\# \#}$ twice a day for 2 weeks. Sutures were removed 12 days after the surgery. Monthly follow-up was scheduled to check the wound healing up to implant insertion.

Postoperative healing was satisfactory and no complications were noted. Six months after surgery, a CBCT scan was taken. The 3D radiographic examination revealed adequate

\footnotetext{
* Ultracain D-S forte, Sanofi-Aventis Deutschland, Frankfurt am Main, Germany.

\# Puros Block Allograft, Zimmer Dental.

** OsteoMed Mincro System, OsteoMed, Addison, TX.

t+ Puros Cortical, Zimmer Dental.

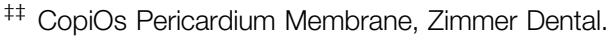

$\S \S$ Gore-Tex 5.0, W. L. Gore \& Associates, Flagstaff, AZ.

IIII Ratiopharm, Ulm, Germany.

ศศ Synflex, Recordati, Milan, Italy.

\#\# Corsodyl, GlaxoSmithKline, Verona, Italy.
} 


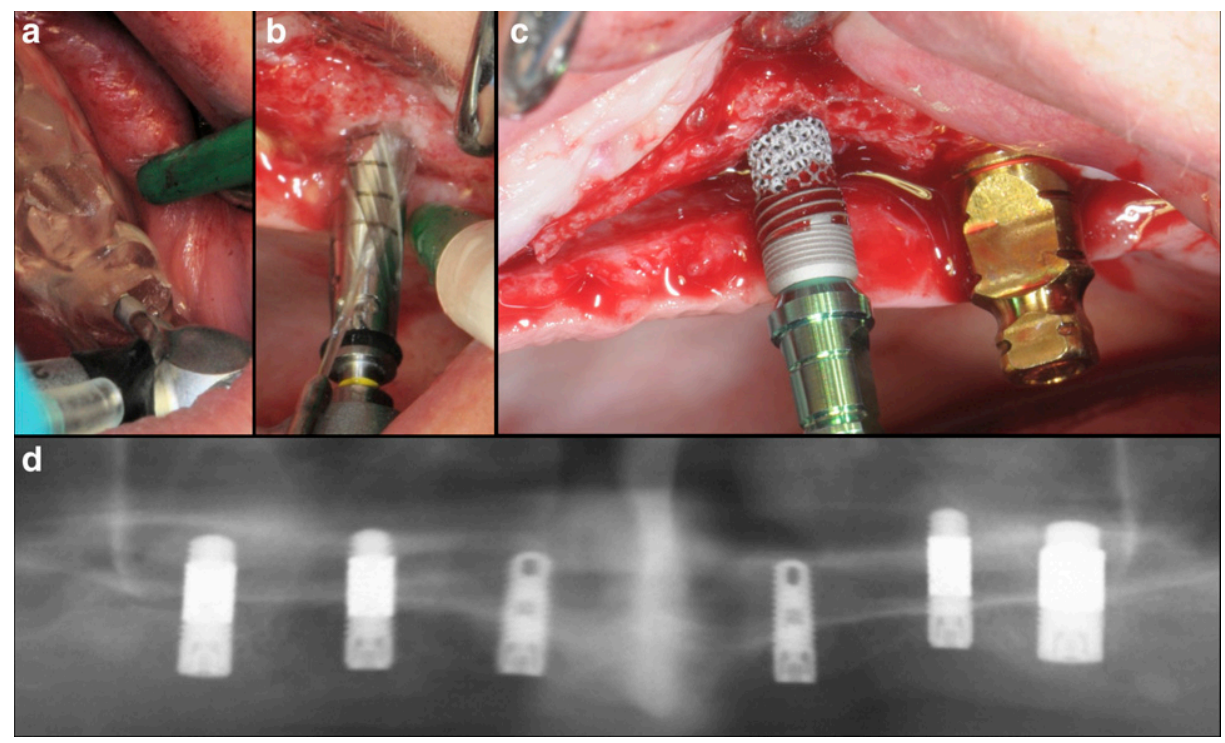

FIGURE 6a Initial osteotomy. 6b Bone sampling. 6c Implant insertion. 6d Panoramic radiograph taken immediately after surgery.

TABLE 1 Implant Site, Diameter, and Length

\begin{tabular}{|l|c|c|c|}
\hline Implant & Site & Diameter $(\mathrm{mm})$ & Length $(\mathrm{mm})$ \\
\hline $1 *$ & 7 & 3.7 & 10 \\
\hline $2 *$ & 10 & 3.7 & 10 \\
\hline $3^{\dagger}$ & 5 & 4.1 & 11.5 \\
\hline $4^{\dagger}$ & 12 & 4.1 & 11.5 \\
\hline $5^{\dagger}$ & 3 & 4.7 & 11.5 \\
\hline $6^{\dagger}$ & 14 & 6.0 & 11.5 \\
\hline
\end{tabular}

* Tapered Screw-Vent implant, Zimmer Dental.

† Trabecular metal implant, Zimmer Dental.

bone formation, which allowed for the proper prosthetically driven implant placement. At the time of implant placement, a significant amount of newly formed bone gain was observed. A surgical guide was fabricated to guide the position of initial osteotomy (Fig. 6a).

Next, a trephine drill $* * *$ (external diameter of $4 \mathrm{~mm}$ and internal diameter of $3 \mathrm{~mm}$ ) was used under saline jet at 600 $\mathrm{rpm}$ to collect bone core specimens in four sites (molar and premolar) before implant insertion (Fig. 6b). A total of six fixtures ${ }^{\dagger \dagger \dagger \ddagger \ddagger \ddagger ~ w e r e ~ p l a c e d ~(F i g s . ~} 6 \mathrm{c}$ and $6 \mathrm{~d}$, Table 1). Flaps were repositioned and secured with single interrupted sutures $\$ \$ \delta$ IIIIII to achieve primary closure. A second-stage procedure was performed 3 months later to uncover the implants (Fig. 7). Reverse torque testing $9 \pi \%$ at $25 \mathrm{Ncm}$ (Figs. $7 \mathrm{~b}$ and $7 \mathrm{c}$ ) and radiography (Fig. 8) confirmed the osseointegration of the implants. The rehabilitation was finalized using a fixed implant-supported full-arch hybrid prosthesis (Fig. 9). The torque value used to tighten the abutment screws was 20 $\mathrm{Ncm}$, as recommended by the vendor.

\section{Histologic Preparation}

Bone core biopsies were fixed, embedded in polymethyl methacrylate and sectioned as described by Soardi et al. ${ }^{16}$
Microradiographs, toluidine blue, or trichrome Gomori staining of $5-\mu \mathrm{m}$-thick sections, photographs, and bone and graft amount evaluations were performed as reported previously. ${ }^{16}$

\section{Clinical Outcomes}

All the implants were integrated, retained, and functional up to the time of the completion of this case report.

CBCT scans, taken at baseline and immediately after implant placement, were superimposed according to a previously published method. ${ }^{17}$ This confirmed that the implants were embedded into purely augmented bone (Fig. 10).

\section{Histologic Outcomes}

Six months after grafting, all biopsies showed formation of a newly formed trabecular bone mixed with allograft residual particles (Figs. 11 and 12). The graft residues were in direct connection with the newly formed bone (Fig. 12). No native bone was found in any sample. The histomorphometric evaluation of the amount of the newly formed bone and residual graft per tissue volume of all biopsies ranged from $21.1 \%$ to $23.6 \%$ and from $3.0 \%$ to $5.2 \%$, respectively.

\section{Discussion}

This clinical case report illustrates that a newly introduced TM implant could be successfully integrated in ridge sites augmented by allografts. It also demonstrates that the 3D block technique is a viable option in augmenting Seibert Class III ridge defects without relying on the traditional autogenous block grafts.

Various surgical techniques have been developed to enter the sinus cavity elevating the sinus membrane and placing

\footnotetext{
*** Stroma, Emmingen-Liptingen, Germany.

t†† Tapered Screw-Vent implant, Zimmer Dental.

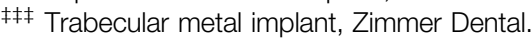

$\S \S \S$ Puros Block Allograft, Zimmer Dental.

IIIII Gore-Tex 5.0, W. L. Gore \& Associates.

ศศ Implantmed, W\&H Dentalwerk, Bürmoos, Austria.
} 

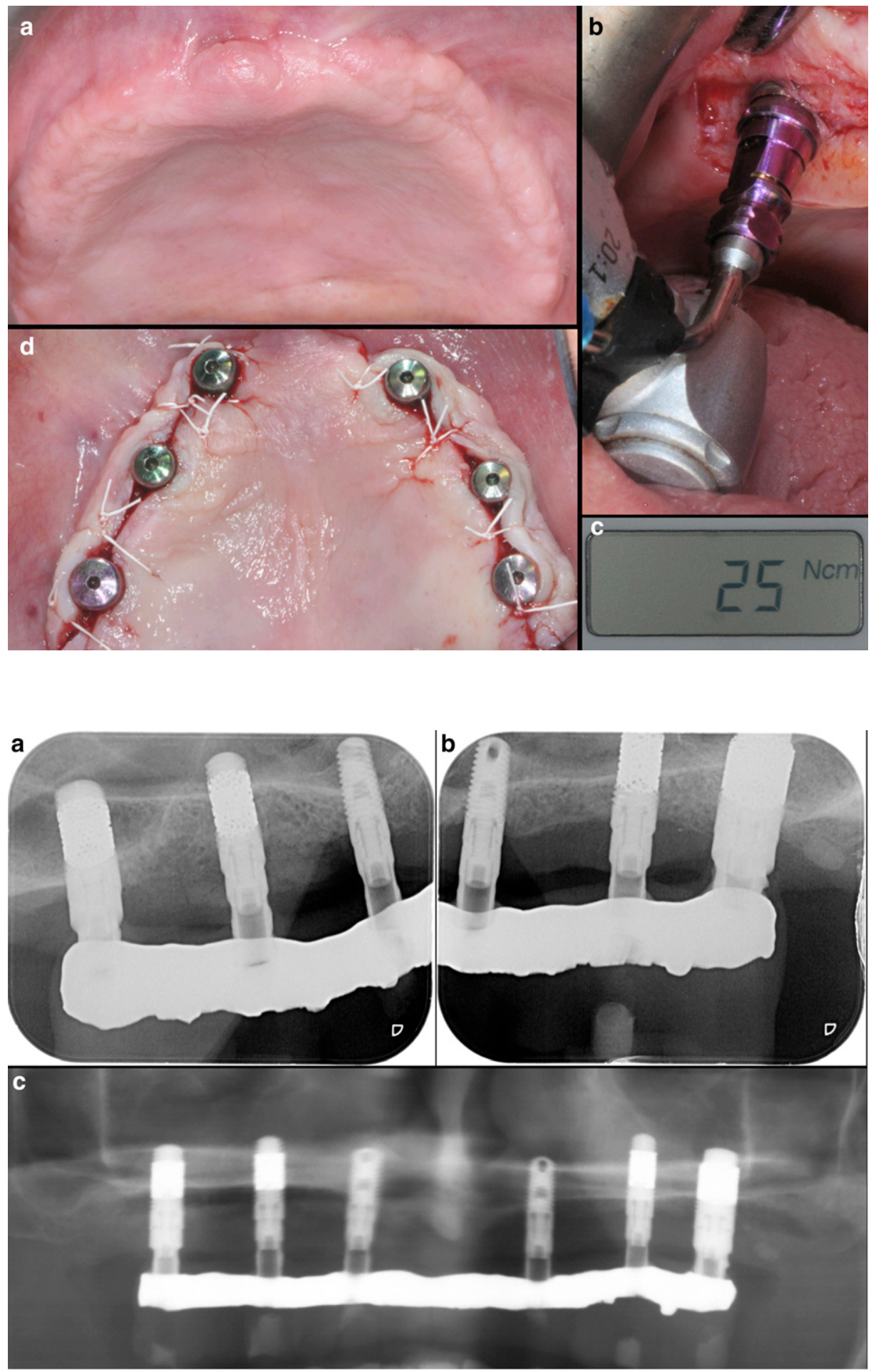

FIGURE 7a Occlusal view, 3 months after implant surgery. $7 \mathrm{~b}$ and $7 \mathrm{c}$ Torque removal test. 7d Occlusal view immediately after secondstage procedure.
FIGURE 8 Periapical ( $8 \mathrm{a}$ and $8 \mathrm{~b}$ ) and panoramic (8c) radiographs taken immediately after final restoration.

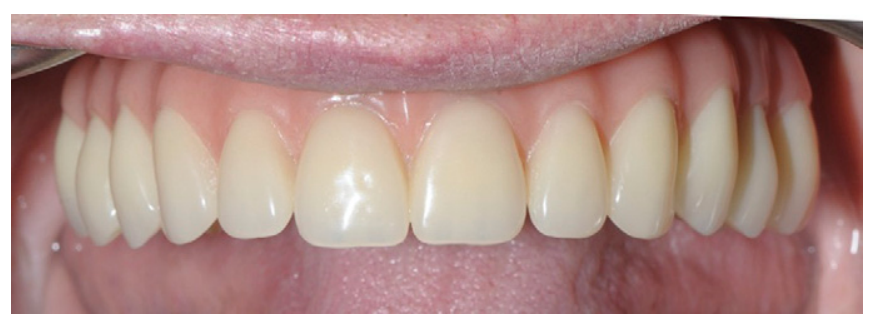

FIGURE 9 Final restoration. bone grafts. In this case report, the decision to apply the lateral or the transcrestal techniques was based on the low amount of residual bone available. It has been noted that the amount of residual bone height significantly influences implant survival after sinus floor elevation; ${ }^{18}$ therefore, it is paramount in treatment planning to identify an appropriate approach to achieve a predictable outcome. In this case report, the right-sided sinus was approached via a traditional maxillary lateral wall osteotomy because the residual floor ranged from 1 to $4 \mathrm{~mm}$. Conversely, 

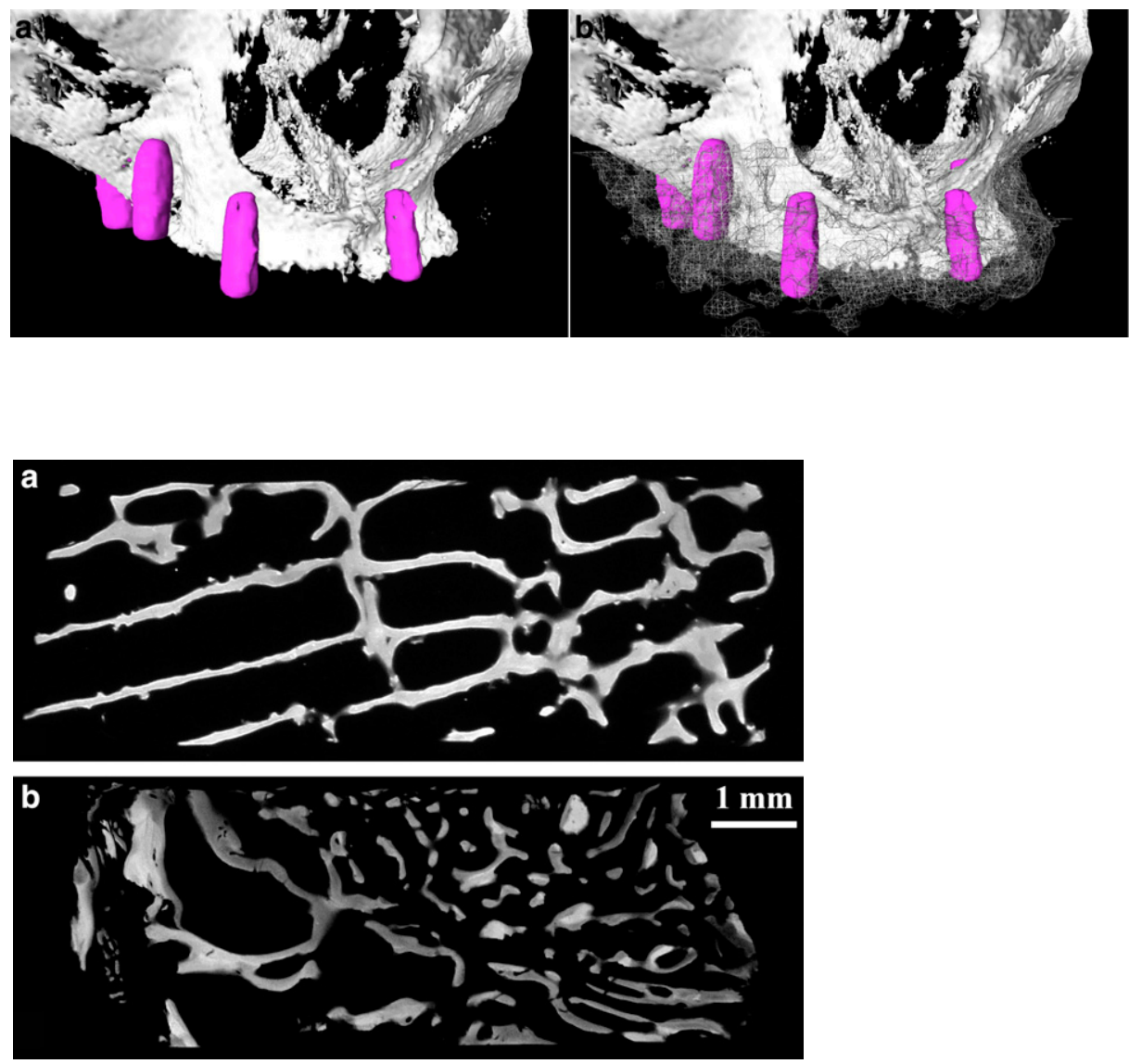

FIGURE 11 Microradiographs of a section of commercially available mineralized human bone allograft block (11a) and of a bone biopsy harvested 6 months after grafting (11b). Note in 11a the more ordered spatial arrangement of the bone trabeculae. Note in 11b how the graft (lighter than the bone) has been greatly replaced by the newly formed bone.
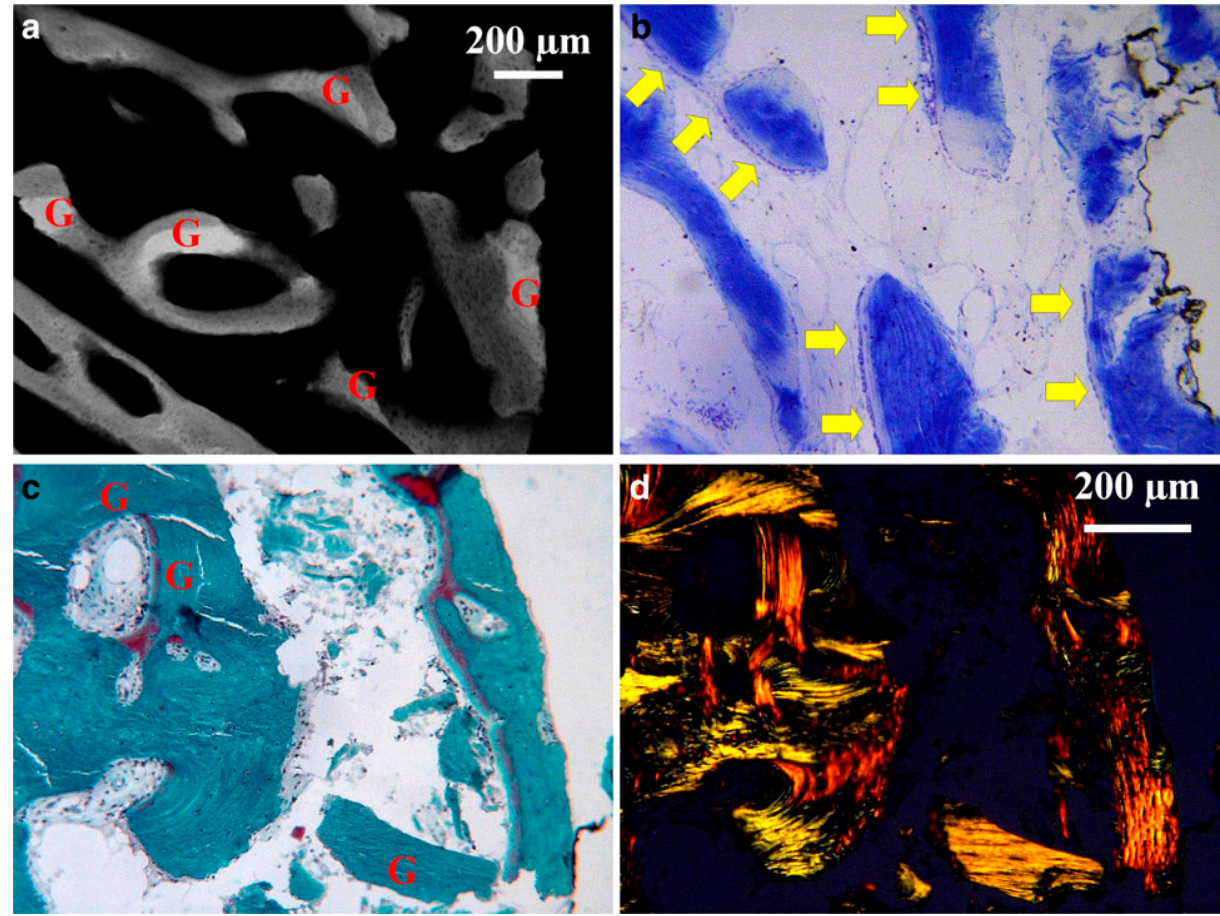

FIGURE 10 Superimposed CBCT scans taken at baseline and immediately after implant placement. 10a Surface reconstruction of native bone (white) and implants (pink). 10b Surface reconstruction of native bone (white), implants (pink), and augmented bone (dark gray).
FIGURE 12 Images illustrating histology of a biopsy harvested 6 months after grafting. Microradiograph (12a), toluidine blue (12b), and trichrome Gomori stain under ordinary (12c) and polarized light (12d). Note in 12a the presence of allograft bone block residues (G). The arrows in $12 \mathrm{~b}$ indicate layers of active osteoblasts (india ink label $=$ crestal bone on the right). Note also in $12 \mathrm{c}$ and $12 \mathrm{~d}$ how the newly formed bone presents a woven or parallel-fibered structure that differs greatly from the lamellar structure of the residual particles $(G)$. 
a crestal approach, which seemed to increase overall implant success rate in extremely atrophic sinus floors in a previous study, ${ }^{15}$ was adopted for the left-sided sinus. Three months after implant placement, all six implants successfully withstood the $25 \mathrm{Ncm}$ reverse torque test. It was argued the TM implant configuration could have yielded additional resistance to reversal rotational force, given the bone in growth into the midsection of the implant. This phenomenon has been documented in orthopedic literature. 3,4 The superimposition of CBCT scans showed that a prosthetically driven implant placement would have not been possible without relying on bilateral sinus augmentation and the 3D block grafts.

Based on the promising results gathered by this clinical report, it is proposed that the rehabilitation of a severely atrophic maxillary arch may be achieved by merging TM implants with new regenerative techniques (e.g., 3D planned human allogenic bone block), thus eliminating the need for bone donor site. Long-term investigations are warranted to verify whether the findings of the present case report are consistent.

\section{Summary}

\section{Why is this case new information?}

What are the keys to successful management of this case?

What are the primary limitations to success in this case?
- To the best of the authors' knowledge, this is the first published clinical case report of a fully functional TM implant.

- A thorough treatment plan, surgical skills, and sufficient financial resources are required.

- There are no long-term studies to show the benefits of TM implants versus conventional implants regarding timing of loading and amount of bone ingrowth and short-term follow-up.

\section{Acknowledgments}

Drs. Hom-Lay Wang and Carlo Maria Soardi have received honoraria for lectures from Zimmer Dental, Carlsbad California, but the authors received no support for this case report. Drs. Clozza and Zaffe report no conflicts of interest related to this case report.

\section{CORRESPONDENCE:}

Dr. Emanuele Clozza, New York University College of Dentistry, Ashman Department of Periodontology and Implant Dentistry, 345 E. 24th St., Suite 3W, New York, NY 10010. E-mail: leleclo@libero.it. 


\section{References}

1. Saulacic N, Bosshardt DD, Bornstein MM, Berner S, Buser D. Bone apposition to a titanium-zirconium alloy implant, as compared to two other titanium-containing implants. Eur Cell Mater 2012;23:273-286.

2. Smith JO, Sengers BG, Aarvold A, Tayton ER, Dunlop DG, Oreffo RO. Tantalum trabecular metal - Addition of human skeletal cells to enhance bone implant interface strength and clinical application. J Tissue Eng Regen Med 2014;8:304-313.

3. Bobyn JD, Stackpool GJ, Hacking SA, Tanzer M, Krygier JJ. Characteristics of bone ingrowth and interface mechanics of a new porous tantalum biomaterial. J Bone Joint Surg Br 1999;81:907-914.

4. Welldon KJ, Atkins GJ, Howie DW, Findlay DM. Primary human osteoblasts grow into porous tantalum and maintain an osteoblastic phenotype. J Biomed Mater Res A 2008;84:691-701.

5. Unger AS, Lewis RJ, Gruen T. Evaluation of a porous tantalum uncemented acetabular cup in revision total hip arthroplasty. Clinical and radiological results of 60 hips. J Arthroplasty 2005;20:1002-1009.

6. Black J. Biological performance of tantalum. Clin Mater 1994;16:167-173.

7. Tsao AK, Roberson JR, Christie MJ, et al. Biomechanical and clinical evaluations of a porous tantalum implant for the treatment of earlystage osteonecrosis. J Bone Joint Surg Am 2005;87(Suppl. 2):22-27.

8. Shuler MS, Rooks MD, Roberson JR. Porous tantalum implant in early osteonecrosis of the hip: Preliminary report on operative, survival, and outcomes results. J Arthroplasty 2007;22:26-31.

9. Buser D. Preface. In: Buser D, ed. 20 Years of Guided Bone Regeneration in Implant Dentistry, 2nd ed. Hanover Park, IL: Quintessence Publishing; 2009:viii.

indicates key references
10. Laurencin C, Khan Y, El-Amin SF. Bone graft substitutes. Expert Rev Med Devices 2006;3:49-57.

11. Reissmann DR, Dietze B, Vogeler M, Schmelzeisen R, Heydecke G. Impact of donor site for bone graft harvesting for dental implants on health-related and oral health-related quality of life. Clin Oral Implants Res 2013;24:698-705.

12. Jacotti M. Simplified onlay grafting with a 3-dimensional block technique: A technical note. Int J Oral Maxillofac Implants 2006;21:635-639.

13. Seibert IS. Reconstruction of deformed, partially edentulous ridges, using full thickness onlay grafts. Part I. Technique and wound healing. Compend Contin Educ Dent 1983;4:437-453.

14. Cicciù M, Risitano G, Maiorana C, Franceschini G. Parametric analysis of the strength in the "Toronto" osseous-prosthesis system. Minerva Stomatol 2009;58:9-23.

15. Soardi CM, Wang HL. New crestal approach for lifting sinus in the extremely atrophic upper maxillae. Clin Adv Periodontics 2012;3: 179-185.

16. Soardi CM, Spinato S, Zaffe D, Wang HL.Atrophic maxillary floor augmentation by mineralized human bone allograft in sinuses of different size: An histologic and histomorphometric analysis. Clin Oral Implants Res 2011;22:560-566.

17. Clozza E, Biasotto M, Cavalli F, Moimas L, Di Lenarda R. Threedimensional evaluation of bone changes following ridge preservation procedures. Int J Oral Maxillofac Implants 2012;27:770-775.

18. Pjetursson BE, Tan WC, Zwahlen M, Lang NP. A systematic review of the success of sinus floor elevation and survival of implants inserted in combination with sinus floor elevation. I Clin Periodontol 2008; 35(Suppl. 8):216-240. 